\title{
DE LA POLÉMICA HUMANISTA EN TORNO A LA CONQUISTA
}

Edudardo Subirats*

\section{$\mathbb{E}_{\text {l cuatro de mayo de } 1493 \text {, apenas }}$} unos meses tras el desembarco del navegante genovés Cristóbal Colón en el puerto de Barcelona, el Papa Alejandro VI, en nombre de su potestad temporal absoluta y universal, concedió a los reyes españoles, que acababan de coronar la Reconquista con la destrucción del reino de Granada y la expulsión de los judíos, el título de legitimidad por derecho absoluto y perpetuo sobre las tierras descubiertas, mediante la bula Inter Cetera: "En virtud de nuestra pura liberalidad, cierta ciencia y plenitud de autoridad apostólica, os damos, concedemos y asignamos a perpetuidad, así a vosotros como a vuestros sucesores los reyes de Castilla y León, todas y cada una de las tierras e islas sobredichas, antes desconocidas, y las descubiertas hasta aquí o que se descubran en lo futuro..." ${ }^{1}$

Cualesquiera sean las posiciones intelectuales frente a la colonización de América, históricamente extrapoladas entre la crítica de la "destrucción de las Indias" y la apología de la acción cristianizadora o civilizadora de la Iglesia romana y la corona española, desde un punto de vista historiográfico no puede menos que asumirse la pluralidad de signifcados que el descubrimiento, la conquista y la subsiguiente "pacificación" encierran. No solamente los crónicas ponen de manifiesto documentariamente esta pluralidad de significaciones, es decir, la tesis de la

* Universidad de la Educación a Distancia, Madrid.

${ }^{1}$ Cf. Bartolomé de Las Casas, Tratados, México 1965, t. II, p.1279. 
Eduardo Subirats

ambigüedad de la empresa colonizadora. También su definicion teológico-política permite reencontrar esta variedad de sentidos. En los tratados de propaganda de la fe los conceptos de descubrimiento, conquista, conversión, predicación, legislación, oficios, aún no siendo precisamente sinónimos, comprenden a pesar de todo un campo semántico uniforme y congruente. Tal sucede en las obras de Ovando y de Acosta. ${ }^{2} \mathrm{Y}$ en el mismo sentido, cuando el Papa Alejandro VI concedió la bula Inter Cetera a los reyes españoles no sólo les otorgaba una potestad temporal sobre los territorios descubiertos por Colón, sino también definía las categorías teológicas programáticas e interdependientes de una compleja empresa que comprendía descubrimientos y ocupación territorial, el despojo y avasallamiento de sus habitantes, al tiempo que la propaganda de la fe, y acción civilizadora a la par que vigilancia doctrinal. Fue aquella bula antes que cualquier otra reflexión o decisión política la que estableció los límites precisos que iban a encerrar el "descubrimiento" de América en el marco estricto de una guerra santa. Y ella la que definía, antes que cualquier otra definición o determinación política, la idea y el proyecto del imperio universal.

Cristóbal Colón, hombre apto y muy conveniente a tan gran negocio y digno de ser tenido en mucho se dice en aquel documento pontificio, con navíos y gentes para semejantes cosas bien apercibidos, no sin grandisimos trabajos, costas y peligros ... hallaron ciertas islas remotisimas y también tierras firmes, que hasta ahora no habían sido por otros halladas, en las cuales habitan muchas gentes que viven en paz, y andan, según se afirma, desnudos, y que no comen carne. Y a lo que dichos vuestros mensajeros pueden colegir, estas mismas gentes, que viven en susodichas islas y tierras firmes, creen que hay un Dios Creador en los cielos, y que parecen asaz aptos para recibir la fe católica y ser enseñados en

${ }^{2}$ Observo esta yuxtaposición y cubrimiento de campos semánticos entre palabras que hoy tendrían una diferenciada defición conceptual en las primeras páginas prologales del tratado de Juan de Ovando, De la Gobernacion spiritual de las Yndias, de 1571. Cf., edicón de Barcelona 1977, p.129. 


\section{EN TORNO A LA CONQUISTA}

buenas costumbres; y se tiene esperanza que, si fuesen doctrinados, se introduciría con facilidad en las dichas tierras e islas el nombre del Salvador, Señor Nuestro Jesucristo...

Se citan programáticamente en la bula pontificia los motivos dominantes de toda una era de confrontaciones, distorsiones y también reconocimientos de la nueva realidad: la idea del paraíso, originalmente introducida por Colón; la visión encendida de las riquezas y de las posibilidades de cristianización que igualmente ocupan las primeras entradas americanas de su diario; ${ }^{3}$ el concepto de "hallazgo" de los nuevos territorios, ${ }^{4}$ que jurídicamente respaldaba su apropiación en nombre del orbis christianus y de su traslación política o imperial, el imperium universalis; el ideario de conversión, que al mismo tiempo definía la empresa de ocupación y explotación territoriales como cruzada a lo ancho de un continente vacío, y al indígena americano como un cristiano en potencia, o como tabula rasa susceptible de sujeción y subjetivación. Incluso el tono persuasivo que implica la mención de una paradisíaca condición del indio, sus creencias monoteístas y su disposición a la indoctrinación cristiana, encuentra en el mismo documento pontificio su contrapunto militante cuando convoca a los monarcas españoles a que "las bárbaras naciones sean deprimidas y reducidas a esa misma fe", o sean "sujetadas y reducidas a la católica fe", $\mathrm{fen}^{5}$ poniendo tales

3 "11 de Octubre ... Ellos andan todos desnudos ... muy bien hechos, de muy fermosos cuerpos y muy buenas caras ... ellos no traen armas ni las cognoçen ... no tienen algún fierro ... ellos deben ser buenos servjdores y de buen yngenjo ... y creo que ligeramente se harían chpistianos, que me pareció que ninguna secta tenjan ... 21 de Hebrero ... bien dixeron los sacros theólogos y los sabios philósophos que el Parayso Terrenal está en el fin de Oriente..." Cristobal Colon, Los cuatro viajes. Testamento, edición de Consuelo Valera, Madrid 1986, p.63 y 194.

${ }^{4}$ El concepto de "hallazgo" y de "descubrimiento" es cuestionado por Francisco de Vitoria en su tratado Relectio de indis: "Pero como aquellos bienes no carecían de dueño, no pueden ser comprendidos en este título (el derecho del descubrimiento. Al principio no se alegaba otro, y con este solo título se hizo al principio Colón, el genovés, a la mar.)." Madrid 1989, p. 85 s.

${ }^{5}$ Esta bula define explícitamente la empresa colonizadora o civilizatoria como cruzada, en la misma medida en que invoca a los reyes españoles a asumirla bajo 


\section{Eduardo Subirats}

gestas al lado de la "recuperación del Reino de Granada" de la "tiranía sarracena", como su efectiva prolongación en tierras lejanas y desconocidas de ultramar. ${ }^{6}$

¿Por qué corre a cargo de la Iglesia y la teología cristiana la concesión territorial americana y, con ella, la definición elemental del principio de colonización? La respuesta es sencilla. Sólo la Iglesia es capaz de legitimar la monarquía universal; sólo el cristianismo puede conceder los títulos legítimos del emperador. En virtud de un principio bíblico, según expone el liberal y reformador Vasco de Quiroga en su tratado De Debellandis Indis. Dios -de acuerdo con su argumentación-concedió el derecho al imperio a Moisés; del mismo modo se lo otorgó Cristo a San Pedro; y asimismo lo concede por este derecho la Iglesia a la corona española. La Iglesia y sólo ella es Mater Imperii. Y ese título también constituye, inversamente, la carta de ilegitimidad del habitante de América sobre sus vidas, sus posesiones y su gobierno: sólo el cristiano es buen gobierno, sólo él es legítimo.

Cruzada y acción pedagógica de instrucción, sujeción violenta y resuelto irreconocimiento de otra forma de vida, liberación del indio y destrucción de sus dioses, sus vidas y sus culturas, paraíso en la tierra e infierno de infieles: esos fueron los ambiguos signos del Descubrimiento. Aquéllos habían sido ya los designios que acompañaron la empresa del propio

el mismo espíritu que la última fase de la Reconquista: "...a imitación de los reyes vuestros antecesores de clara memoria, propusisteis con el favor de la divina clemencia sujetar las susodichas islas y tierras firmes, y los habitantes y naturales de ellas reducirlos a la fe católica". Cf. traducción castellana de la bula en Bartolomé de Las Casas, Tratados, op.cit., t.II, p.1284 s.

${ }^{6}$ Después de Al-Andalus Jerusalén: tal la consigna de la Hermandad de los Caballeros de Avila en 1172. "Aunque los papas estimaban que los españoles debían luchar con los musulmanes en España y no en Tierra Santa -escribe Lomax-muchos españoles pensaban con Alfonso que una vez que se pusiese punto final a la Reconquista había que cruzar el mar para lanzarse sobre el mismísimo corazón del Islam". Cf. Derek W. Lomax, La Reconquista, Barcelona, 1984, p.110. La sagrada Tenoxtitlán se convirtió en el sucedáneo de la Ciudad Santa.

${ }^{7}$ Vasco de Quiroga, De Debellandis Indis, René Acuña (ed.), México 1988, p.155 y 177 . 
EN TORNO A LA CONQUISTA

Colón: evangelización del mundo, conquista de la "Casa Santa" de Jerusalén, descubrimiento del paraíso terrenal. ${ }^{8}$

Desde el punto de vista discursivo, sin embargo, la yuxtaposición rapsódica de estos aspectos diferenciados desoculta una consistencia y una concatenación interiores tan pronto se tiene en cuenta el proceso de dominación que sus categorías teológico-políticas encierran. No se trata solamente de una reconstrucción historiográfica de las etapas de la conquista. Tal periodización es importante. Pero sólo en la medida en que sus diferencias políticas, sus etapas estratégicas o su evolución teológico-jurídica sean comprendidas, al mismo tiempo, como figuras conceptuales de un mismo proceso social de conversión, subyugación, subjetivación y emancipación cristianas. Sólo en la medida en que estos aspectos puedan ser comprendidos analíticamente a lo largo de un discurso continuo, o sea, de una misma lógica y una misma teología de la colonización.

En una obra ya clásica sobre el descubrimiento y conquista americanos, el estudio de Georg Friederici, se distinguía al mismo tiempo dicha periodización historiográfica de la conquista, al tiempo que su articulación interior:

Tenemos, en pirmer lugar, el período de la brutal, violenta y asoladora conquista... sigue un período de intentos de penetración pacífica y de expansión lenta, pero ya no con las armas del soldado, sino con la labor del misionero y colono. Al comprender que estos esfuerzos de penetración pacífica, en el sentido preconizado por el P.Las Casas, estaban condenados, en muchos lugares, a fracasar, hacia fines del siglo XVII, hacia el año 1660 , prodújose un nuevo viraje en la opinión pública. Diríase que reverdecía el espíritu de la Conquista... A este breve período de reacción siguió el cuarto y último, que duró hasta el final de la dominación española en América: la conquista pacífica por medio de las Misiones, apoyada

${ }^{8}$ Alain Milhou, Colón y su mentalidad mesiánica en el ambiente franciscanista español, Valladolid 1983, p. 41 s. 
Eduardo Subirats

en guarniciones militares y seguidas más tarde por aglomeraciones de colonos...

Espléndida síntesis. Sin duda, hubo un primer momento pionero de la colonización americana: período dorado dominado por la presencia de aventureros resueltos y sin ley. Se lo puede designar como el momento heroico de la conquista. Fue algo así como un período fundacional del descubrimiento y sujeción de nuevos territorios y sus habitantes. En esta etapa originaria de la historia americana moderna resulta muchas veces difícil distinguir entre el aventurero criminal y el héroe cristiano. Pero es esa etapa de la expansión europea en América la más colorística: los signos de la perplejidad, el entusiasmo y el terror ante un mundo radicalmente otro, que Europa sentía rendido a sus pies, se adorna con todos los atributos literarios de un epos legendario y mítico. Las Cartas de Cortés, la crónica de Díaz del Castillo, los relatos del naufragio de Nuñez de Vaca recorren distintamente esos momentos.

Luego las cosas parecen adquirir la apariencia de una forma institu32 cionalmente sancionada, tanto por la Iglesia romana, como por la corona. Esta primera figura de legitimidad jurídica se instituye a partir de 1512 . Son los requerimientos. Su principio responde por un primitivo concepto de guerra santa. Ese era, al fin y al cabo, el significado de la conquista que había canonizado la bula papal. "...Si vosotros, informados de la verdad, os quisiéreis convertir a la santa fe católica... pero si no lo hiciéreis o en ello dilación maliciosamente pusiéreis, certifícoos que con la ayuda de Dios yo entraré poderosamente contra vosotros y vos haré guerra por todas partes y manera que yo pudiere y os sujetaré al yugo y obediencia de la Iglesia y de su Majestad... ${ }^{10} \mathrm{Al}$ principio de guerra total no sólo le sucedió esta figura de su interiorización, y del terror como ley y orden sagrados, la primera forma legal de identidad histórica hispanoamericana, sino que ésta explica y da un sentido a aquélla. El terror brutal

${ }^{9}$ Georg Friederici, El carácter del descubrimiento y de la conquista de America, Mexico 1973, p.323 s.

${ }^{10} \mathrm{Cf}$. Lewis Hanke, Estudios sobre Bartolomé de Las Casas y la lucha por la justicia en la conquista española de América, Caracas, 1968, p.92. 


\section{EN TORNO A LA CONQUISTA}

de la violencia inmediata había adquirido con ello una primera dimensión interior que lo justificaba tanto política como teológicamente, aunque de ningún modo lo suprimía.

A partir de 1573, la corona española prohibió legalmente la palabra "conquista". Su significado fue suplantado sumariamente por el concepto de "pacificación", ya antes utilizado por Cortés tan pronto había conquistado militarmente los principales centros político-religiosos de México. El valor teológico-político del nuevo término estratégico de pacificación entrañaba una nueva figura del no-reconocimiento de la existencia del indígena, marcadamente diferente de aquélla a la que obligaba el requerimiento: abandonar y destruir los ídolos, y con ellos su forma de vida; aceptar el bautizo formal, y con ello someterse jurídica y moralmente al nuevo poder... La estrategia y el concepto de pacificación presuponían la prerrogativa absoluta, por parte del conquistador, de imponer el sistema de un orden a la vez político y teológico. Prerrogativa absoluta: o sea, como si se trazara por primera vez una ley sobre un desierto sin nombre ni orden. Era el acto mítico, ensalzado y consagrado sacramentalmente por el bautismo, por la imposición de nombres a todos los seres humanos y a todas las cosas. Como al comienzo de la creación. Pacificación significaba virtualmente poner un orden allí dónde reinaba el caos originario, la nada. Lo que significaba reconocer al habitante de América como un sujeto carente de civilización: "los mantenemos en paz -rezan las Ordenanzas de Felipe II, del 13 de julio de 1573- para que no se maten, ni coman, ni sacrifiquen, como en algunas partes se hacía; y puedan andar seguros por todos los caminos, andar y contratar y comerciar..." ${ }^{11}$ Es bajo esa concepción legalmente reformada que el indio recibía formal y positivamente una nueva libertad. Una insólita libertad, es cierto. En su nombre fue expulsado de sus formas de vida y despojado su memoria histórica. El nuevo principio de la interioridad cristiana lo absolvió automáticamente de su comunidad originaria y le definió institucionalmente como el nuevo hombre: un sujeto vacío pero virtualmente libre, dependiente realmente de las instancias políticas y eclesiásticas que

${ }^{11}$ Ibid., p.100. 
Eduardo Subirats

lo sometían a la servidumbre y la miseria, pero teóricamente redimido en la fe, a través de la culpa y su redención sacramental.

Toda la teoría política de Las Casas y una parte de los dominicos, de la Escuela de Salamanca, e incluso de la independencia americana, nace de esta primera figura de la emancipación indígena, a la vez signo moderno de una nueva libertad frente a los excesos y la crueldad de conquistadores y encomenderos; y principio de una forma articulada y compleja de deuda interiorizada, y, por consiguiente, de vasallaje y subjetivación. Se trata de una figura o constelación a la vez político-teológica y subjetiva que entraña la sujeción voluntaria a un sistema o a un princpio racional, sin embargo heterónomo y heterónomamente impuesto, y que asimismo presupone la interiorización del terror como princpio de subjetivación; encerrando en esa dimensión interior aquella violencia inmediata de la guerra de conquista y vasallaje como su último fundamento teológico.

Una nueva conciencia, que no es heroica, pero tampoco idealista ni utópica, surgió a partir de la segunda mitad del siglo XVI bajo las exigencias pragmáticas de la organización política de las vastas colonias de ultramar. De acuerdo con ella el indio ya no era el desconocido Otro al que cristiano europeo proyectara a discreción su propio imaginario mitológico e histórico, luego de embargarle sus dioses y su lengua, sus bienes materiales y también su memoria histórica: el moro diabólico, el adamita inocente, el judío condenádo por el dios Verdadero... Y tampoco era aquella conciencia inofensiva e ingenua que garantizaban los sistemas teológico-políticos de utopías trascendentes como la de un Las Casas o un Vitoria. Por primera vez se reconoce al americano en su existencia real, en su resistencia enconada contra la identidad y las formas de vida que le imponía el invasor. Por primera vez estos frailes y misioneros entendieron la necesidad de explorar el imaginario indígena para penetrar en su estructura con estrategias de dominación específicas, más refinadas y eficaces. Ésta era formulada ahora como proceso de racionalización interior, de transparencia sacramental y jurídica del nuevo hombre americano, de autocontrol y dominio subjetivados. Por primera vez se formuló un programa expreso de reconocimiento del indígena en su realidad histórica, ética, psicológica y social, o sea de una antropología 
EN TORNO A LA CONQUISTA

teológica con fines pragmáticos de propaganda, catequesis y transformación sacramental de las formas de vida.

Los tratados de propaganda de la fe y de doctrina cristiana, y los manuales para la utilización sistemática del confesionario como nuevo instrumento de violencia interna sucedieron así a los tratados de guerra justa. Un nuevo principio de colonización se había cristalizado ante el reconocimiento del último bastión de la resistencia contra el europeo. Se inauguraba la noción antropológica, empírica, racional y moderna de reconocimiento del indio bajo el aspecto de las formas de sensibilidad frente a la naturaleza y el existente humano, los valores del mundo imaginario, colectiva e individualmente considerado, las formas que otorgaron un sentido íntimo al amor, a la familia y la vida cotidiana, los más secretos deseos, los estratos profundos de la fantasía y la aspiración individual a la felicidad. "Aquí, pues, conviene -escribe J. de Acosta en su tratado de propaganda cristiana De procuranda indorum salute-que asiente al pie el catequista, y para arrancar las últimas raíces de la idolatría del ánimo de los indios, ponga su pensamiento, su industria y su trábajo" ${ }^{12}$

Esta periodización historiográfica distingue tres etapas, lógicamente definidas, con arreglo a un criterio político, militar y jurídico. El proceso de colonización no sólo partía, sin embargo, de una legitimación teológico-eclesiástica: "el imperio reside enteramente en la Iglesia", como decía a este respecto liberal misionero Vasco de Quiroga. ${ }^{13}$ La colonización arrancaba también de un decisivo impulso religioso. Movía el afán de riquezas, pero también la fe. Esta fe se remontaba históricamente a los comienzos de la Reconquista, a sus héroes y sus mitos. La Reconquista, la lucha cristiana contra el Islam de la que surge la identidad religiosa y de casta de lo español, constituyó aquel período previo y fundacional que condicionaba y anticipaba en una medida importante las normas decisivas del proceso y la suerte de la conquista americana.

La "guerra divina" española, vigente, de acuerdo con Américo Castro hasta el siglo XIX, pero cuyos signos de heroismo y trascendencia se sienten incluso en el ensayo español del siglo $\mathrm{XX}$, prolongaba su predo-

12 De procuranda, op.cit., p. 460.

${ }^{13}$ Vasco de Quiroga, De Debellandis Indis, op.cit, p. 152-3. 


\section{Eduardo Subirats}

minio sin solución de continuidad en América. Su soberano emblema identificatorio de Santiago, "credo afirmativo lanzado contra la muslemia, bajo cuya protección se ganaban batallas que nada tenían de ilusorias", ${ }^{14}$ siguió manteniendo su papel unificador y glorificador en esa penúltima etapa de la cruzada de España.

El proceso colonizador solamente puede entenderse a partir de un punto de vista sociológico, político y militar desde esta perspectiva de su continuidad con la guerra contra el Islam. Así también su sentido interior; sus significados espirituales o ético-religiosos, sus categorías estratégicas más generales, se formularon y se encuentran en los postulados teológicos de la universalidad de la salvación cristiana y el principio de expansión que le es inherente. La lógica de la colonización, la reconstrucción de aquel proceso conceptual que establece un principio de dominación y dependencia en el discurso cultural y racional constitutivo de un orden a la vez civilizatorio y subjetivo, fue en primer lugar una teología de la colonización.

Lo fue por su distintivo afán de conversión, por su ideario original de guerra santa, por sus características heroico-misionarias de redención mesiánica y salvación o emancipación humana, por la institución eclesiástica que representa vicariamente la potestad redentora de la cruz, en la que se respaldaba social y moralmente la identidad del nuevo hombre americano. Decir que el proceso de la conquista, colonización, aculturación etc., expresa o comprende una "teología de la colonización" quiere decir que la guerra contra indios, el genocidio, el nuevo orden de las instituciones políticas, económicas o penitenciarias en las colonias españolas, la esclavitud o la tortura sólo fueron pensadas globalmente como una estrategia de salvación cristiana. Lo que nos parece cínico-las frases grandilocuentes de Sepúlveda sobre la muerte y el dolor infligido sobre indios como acto de caridad cristiana, o las estrategias de conversión definidas por Acosta como ilustración y defensa de la libertad de los

${ }^{14}$ Américo Castro, La realidad histórica de España, México, 1965, p.357. Sobre la continuidad de la cruzada hispánica contra el Islam y la conquista puede consultarse una interpretación clásica, de 1925, como la de Friedirici, op.cit., p. $331 \mathrm{~s}$. 


\section{EN TORNO A LA CONQUISTA}

indios de su anterior servidumbre a su diabólica historia y monstruosas formas de vida-fue un principio de inconstestable heroísmo cristiano y caballeresco. El significado de esta salvación estaba relacionado con la creencia cristiana en un reino del más allá. Sin embargo esta trascedencia tenía una función visible y tangible en el más acá de las formas concretas de vida de los nuevos súbditos: la configuración de una conciencia, de una idcntidad, ligada al mismo tiempo a un proceso de autorreflexión y a las instituciones del poder colonial. La salvación cristiana coincide profundamente con el proceso de liquidación de la memoria histórica americana, y los vínculos comunitarios que desde la lengua hasta las fiestas lo sostenían. Ella en fin está relacionada con la configuración sustitutiva de una nueva conciencia moderna, es decir subjetiva y racional, por la mediación de la cruz. Tal fue el sentido profundo de la "destruccion de las Indias" aquende el espectáculo de crueldad y tiranía europeas. 